\title{
Wild bitter gourd improves metabolic syndrome: A preliminary dietary supplementation trial
}

\author{
Chung-Huang Tsai ${ }^{1,2}$, Emily Chin-Fun Chen ${ }^{2}$, Hsin-Sheng Tsay ${ }^{2 *}$ and Ching-jang Huang ${ }^{3,4^{*}}$
}

\begin{abstract}
Background: Bitter gourd (Momordica charantia L.) is a common tropical vegetable that has been used in traditional or folk medicine to treat diabetes. Wild bitter gourd (WBG) ameliorated metabolic syndrome (MetS) in animal models. We aimed to preliminarily evaluate the effect of WBG supplementation on MetS in Taiwanese adults.

Methods: A preliminary open-label uncontrolled supplementation trial was conducted in eligible fulfilled the diagnosis of MetS from May 2008 to April 2009. A total of 42 eligible (21 men and 21 women) with a mean age of $45.7 \pm 11.4$ years (23 to 63 years) were supplemented with 4.8 gram lyophilized WBG powder in capsules daily for three months and were checked for MetS at enrollment and follow-up monthly. After supplementation was ceased, the participants were continually checked for MetS monthly over an additional three-month period. MetS incidence rate were analyzed using repeated-measures generalized linear mixed models according to the intention-to-treat principle.

Results: After adjusting for sex and age, the MetS incidence rate (standard error, $p$ value) decreased by $7.1 \%$ (3.7\%, $0.920), 9.5 \%(4.3 \%, 0.451), 19.0 \%(5.7 \%, 0.021), 16.7 \%(5.4 \%, 0.047), 11.9 \%(4.7 \%, 0.229)$ and $11.9 \%(4.7 \%, 0.229)$ at visit $2,3,4,5,6$, and 7 compared to that at baseline (visit 1), respectively. The decrease in incidence rate was highest at the end of the three-month supplementation period and it was significantly different from that at baseline $(p=$ 0.021). The difference remained significant at end of the 4th month (one month after the cessation of supplementation) ( $p=0.047$ ) but the effect diminished at the 5 th and 6 th months after baseline. The waist circumference also significantly decreased after the supplementation $(p<0.05)$. The WBG supplementation was generally well-tolerated.
\end{abstract}

Conclusion: This is the first report to show that WBG improved MetS in human which provides a firm base for further randomized controlled trials to evaluate the efficacy of WBG supplementation.

Keywords: Clinical trial, Metabolic syndrome, Momordica charantia, Supplementation, Waist circumference

\section{Introduction}

Bitter gourd (Momordica charantia L.; BG) is a common tropical vegetable that has also been used in the traditional medicine. BG's anti-diabetic, anti-bacterial, antiviral and anticancer activities have been scientifically demonstrated in past decades [1,2]. Among these, the anti-diabetic activity and possible mechanisms of BG have been demonstrated in molecular, cellular and animal models as well as in human studies and extensively

\footnotetext{
* Correspondence: hstsay@cyut.edu.tw; cjjhuang@ntu.edu.tw

${ }^{2}$ Graduate Institute of Biochemical Sciences and Technology, Chaoyang

University of Technology, Wufong, Taichung 41349, Taiwan

${ }^{3}$ Department of Biochemical Science and Technology, National Taiwan

University, Taipei 106, Taiwan

Full list of author information is available at the end of the article
}

reviewed [3-5]. In addition, BG has been shown to ameliorate metabolic syndrome (MetS) in animal studies [6-8]. Nevertheless, it remains unclear if BG has beneficial effects on MetS in human.

MetS is a metabolic disorder characterized by the clustering of risk factors including: abdominal obesity, dyslipidemia, hypertension and insulin resistance, and is well-established for predicting high risks of type 2 diabetes mellitus (DM), cardiovascular diseases [9] and all causes mortality [10]. Due to rapid transitions toward excessive energy intake and sedentary lifestyle, MetS has become a major health problem worldwide affecting about $34 \%$ of US [11] and $23.1 \%$ of Taiwan populations [12].

\section{Biomed Central}

(c) 2012 Tsai et al; licensee BioMed Central Ltd. This is an Open Access article distributed under the terms of the Creative Commons Attribution License (http://creativecommons.org/licenses/by/2.0), which permits unrestricted use, distribution, and reproduction in any medium, provided the original work is properly cited. 
Insulin resistance, which leads to derangements in carbohydrates and lipid metabolism, is considered to play a central role in MetS. Peroxisome proliferator-activated receptors (PPARs) are nuclear receptors that control lipid and carbohydrate metabolism. These receptors are regarded as important targets for treating MetS [13]. BG extract activated PPAR $\alpha$ [14] and PPAR $\gamma[15,16]$, and thus were recognized as a PPAR $\alpha / \gamma$ dual agonist [17]. In animal models, BG up-regulated PPAR $\gamma$ and PPAR $\alpha$-mediated pathways which is associated with improved MetS $[6,18]$. Together with other evidences that BG improved insulin signaling [8], BG is considered a potential "traditional Chinese medicines" in treating MetS [19].

To date, most published human clinical trials on BG were focused on the blood glucose control [20], very few were on the MetS. This study aimed at preliminarily exploring the potential effects of WBG on MetS. It is anticipated to learn from this preliminary study the safety, feasibility and validity of experimental design, including subject inclusion and exclusion criteria, dosage, period of supplementation, length of washout period, endpoint for examination, etc., to support double blind, randomized-placebo controlled clinical trials in the future.

\section{Materials and methods Materials}

Fresh Hualien No. 4 wild bitter gourds (Momordica charantia L.; WBG) were developed, cultivated and provided by Hualien District Agricultural Research and Extension Station, Council of Agricultural, Executive Yuan, Taiwan. This specific hybrid strain was selected based on its high activity in the PPAR transactivation assay. A total of $502.8 \mathrm{~kg}$ fresh WBG (whole fruit including seeds) was lyophilized and pulverized. The dried WBG powder $(27.4 \mathrm{~kg}$ ) was filled into capsules (480 $\mathrm{mg}$ in each). The preparation of WBG capsules from fresh WBG was conducted by a GMP factory (Family Satisfied BIO-CHEM Co., Changhua, Taiwan) under our instruction and supervision.

\section{Subjects and Design \\ Study subjects}

The study was approved by the Institutional Review Board (IRB) of Cheng Ching Hospital (Taichung, Taiwan). Candidates ( $\geq 20$ years) were recruited at this hospital and screened. Eligible subjects were invited and informed of the purpose and risks of the study and their written informed consents were obtained.

\section{Definition of MetS and Exclusion criteria}

Candidates having three or more of the following five features met the diagnostic criteria for MetS: (1) waist circumference $\geq 90 \mathrm{~cm}$ in men and $\geq 80 \mathrm{~cm}$ in women, (2) serum triglyceride $\geq 150 \mathrm{mg} / \mathrm{dL}$, (3) high density lipoprotein cholesterol (HDL-c) $<40 \mathrm{mg} / \mathrm{dL}$ in men and $<50 \mathrm{mg} / \mathrm{dL}$ in women, (4) blood pressure $\geq 130 / 85 \mathrm{~mm}$ $\mathrm{Hg}$, and (5) serum glucose $\geq 100 \mathrm{mg} / \mathrm{dL}[9,21]$. Major exclusion criteria included: serum alanine aminotransferase $\geq 100 \mathrm{IU} / \mathrm{L}$ (3 times the upper limit of normal value), total bilirubin $\geq 2.0 \mathrm{mg} / \mathrm{dL}$, creatinine $\geq 2.0 \mathrm{mg} /$ $\mathrm{dL}$, glycosylated hemoglobin (HbA1c) levels $\geq 9.0 \%$, women of childbearing potential not using adequate contraception [2], diagnosed myocardial infarction, unstable angina or cerebral vascular attack in the previous six months, receiving vigorous exercise training, weight control with diet or drug, presence of conditions affecting compliance (i.e., drug, alcohol abuse or psychiatric problems), and unwillingness to consent. Those with allergies to foods of the melon family and with known G6PDH deficiency [2] were also excluded.

\section{Sample size estimation}

The estimation of the sample size was based on a $15 \%$ decrease in the incidence rate of MetS. As such, the investigation had more than $80 \%$ power to detect any $15 \%$ decrease in the incidence rate of MetS status at a significance level of 0.05 . The expected dropout rate was $5 \%$. More than 45 eligible patients were targeted for recruitment.

\section{Study Design}

This preliminary trial was regarded as a phase II (exploratory efficacy)-like study using an open-label single-arm design to generate hypothesis, to determine the safety (adverse effect) and to provide justification for a large-scale multicenter clinical trial in the future. Based on our previous animal study and the study reported by Jayasooriya et al [22], 1\% (w/w) WBG in the diet significantly improved hyperglycemia and lipid metabolism. The dose of supplementation in this study was set at 4.5-5.0 g WBG/day as Taiwanese 24-hour diets were estimated to weigh $450-500 \mathrm{~g}$ on a dry basis [23]. Studied subjects were instructed to take three, three and four capsules with their three daily meals without altering their usual dietary and exercise habit. The MetS risk factors were monitored monthly throughout the three successive months of supplementation. After the cessation of supplementation, MetS risk factors were continually followed up over an additional three-month period. Thus, a total of seven visits was needed to complete the study (visit 1 was the baseline before the supplementation started). At each visit, subjects were interviewed regarding compliance and adverse events. Physical examination and blood specimen collection were also performed.

\section{Endpoints \\ Efficacy}

The primary efficacy endpoint (outcome measurement) was a decline in the $\%$ MetS incidence after the 
intervention, while the secondary efficacy endpoints were the 5 diagnostic criteria for MetS and the insulin resistance indicators including homeostasis model assessment (HOMA), logHOMA, quantitative insulin sensitivity check index (Quicki) and McAuley index. These indicators were calculated as the followings: HOMA $=$ insulin $(\mu \mathrm{U} / \mathrm{mL}) \times 0.8$ glucose $(\mathrm{mg} / \mathrm{dL})$; QUICKI $=1 /[\log$ insulin $(\mu \mathrm{U} / \mathrm{mL})+\log$ glucose $(\mathrm{mg} /$ $\mathrm{dL})$ ]; McAuley Index $=\exp$ [2.63-0.28 $\ln$ insulin $(\mu \mathrm{U} /$ $\mathrm{mL})-28.35 \mathrm{ln}$ triglycerides $(\mathrm{mg} / \mathrm{dL})]$. Decreases of Homa \& $\log$ Homa as well as increases of QUICKI and McAuley index values indicate the amelioration of insulin resistance.

\section{Safety}

In human trials of $\mathrm{BG}$, the most commonly reported side effects are abdominal pain and diarrhea [24]. Aside from adverse events, other surrogate laboratory safety endpoints monitored were serum creatinine, hepatic transaminases (alanine aminotransferase and aspartate aminotransferase), $\gamma$-glutamyl transferase, alkaline phosphatase, total bilirubin, sodium and potassium.

\section{Physical examination}

Weight, height, waist circumference, and blood pressure were measured by trained nurses, who also took blood samples. Weight and height were measured to the nearest $0.1 \mathrm{~kg}$ and $0.1 \mathrm{~cm}$, respectively. Body mass index (BMI) was calculated as body weight in kilograms divided by the square of height in meters. Waist circumference was measured midway between the costal margin and iliac crest to the nearest $0.1 \mathrm{~cm}$. At each visit, the blood pressure was measured 3 times with manual mercury sphygmomanometer and the mean value was recorded.

\section{Blood specimen collection and analysis}

Fasting blood specimens were collected after an eighthour overnight fast. The blood samples were sent to the clinical laboratory of Cheng Ching Hospital for analysis within one hour. Anti-coagulated whole blood was used to determine erythrocyte count, leukocyte count, hemoglobin, and platelet count using a Cell Dyn ${ }^{\circledR} 3500$ hematology AutoAnalyzer (Abbott Laboratories, Dallas, TX, US). Biochemical tests were performed using a Hitachi ${ }^{\circledR}$ 747 analyzer (Roche Diagnostics, Mannheim, Germany).

\section{Data Analysis}

Significance of the change in the MetS incidence rate was analyzed by the repeated-measures generalized linear mixed model (GLMM). Those of the secondary efficacy endpoints which were continuous variables were analyzed by the linear mixed model (LMM). Irrespective of whether the study subject has completed the whole study or not, data of the 42 study subjects were all included in the statistical analyses based on the "intention-to-treat" principle to avoid bias. The $p$ values set the significance level at 0.05 were one-sided. The IBM SPSS $^{\mathbb{B}} 19.0$ for Windows was utilized to perform all the statistical analyses.

\section{Results}

\section{Study Subjects}

Among 58 participants assessed for eligibility, 42 (72.4\%) met the inclusion criteria of MetS and 16 (27.6\%) were excluded including 10 not meeting inclusion criteria and 6 refusing to participate in this trial. Among the 42 eligible enrolled, 38 completed the trial. The reasons of withdrawals were: two went abroad and two discontinued because of dizziness and headache.

Of the 42 study subjects, 21 (50\%) were men and 21 (50\%) were women. The study subjects had a median age (inter-quartile range; IQR) and mean age (range) of 49 years (35-54), $45.7 \pm 11.4$ years (23-63) respectively. Test of normality of age with Shapiro-Wilk test showed that $p$-value is 0.096 , indicating that these data are from a normally distributed population. Eighteen (42.9\%), 18 (42.9\%) and $6(14.3 \%)$ with 3, 4 and 5 criteria of MetS respectively were noted. Among the 42 subjects, 40 (95.2\%) had abdominal obesity (based on waist circumference), 14 (33.3\%) were overweight $(24<\mathrm{BMI}<27$ $\left.\mathrm{kg} / \mathrm{m}^{2}\right)$ and $26(61.9 \%)$ were obese $\left(\mathrm{BMI} \geq 27 \mathrm{~kg} / \mathrm{m}^{2}\right)$. The numbers of subjects with other MetS risk factors were 26 (61.9\%) with serum glucose $\geq 100 \mathrm{mg} / \mathrm{dL}, 34$ (81.0\%) with serum triglyceride $\geq 150 \mathrm{mg} / \mathrm{dL}, 25$ (59.5\%) with low HDL-c and 36 (85.7\%) with SBP $\geq 130$ or DBP $\geq 85$ $\mathrm{mmHg}$. Additional characteristics of the study subjects included: tobacco use 7 (16.7\%), alcohol consumption 2 (4.8\%), betel nut chewing $1(2.4 \%)$ and exercise 14 (33.3\%).

The baseline characteristics of the 42 subjects, stratified by gender, are presented in Table 1 . The following characteristics were significantly different between genders: body height, HDL-c, alanine aminotransferase, aspartate aminotransferase, $\gamma$-glutamyl transferase, total bilirubin, creatinine, uric acid, homocysteine, testosterone, C-reactive protein, red blood cell, hemoglobin, platelet, HOMA and McAuley index. No significant differences were noted between the two groups in terms of age, body weight, body mass index, waist circumference, blood pressure, heart rate, fasting glucose, glycosylated hemoglobin A1c, triglyceride, low density lipoprotein cholesterol (LDL-c), cholesterol, alkaline phosphatase, insulin, fibrinogen, white blood cell, $\operatorname{logHOMA}$ and Quicki.

\section{Effects of WBG on MetS}

Changes in the incidence rate of MetS throughout the study are shown in Figure 1. The GLMM analyses were 
Table 1 Baseline characteristics and differences between genders $(n=42)$

\begin{tabular}{|c|c|c|c|c|c|}
\hline Variables & Men mean & SEM $^{a}$ & Women mean & SEM $^{\mathrm{a}}$ & $p$ value $^{\mathrm{b}}$ \\
\hline Age (year) & 46.9 & 2.7 & 44.4 & 2.3 & 0.487 \\
\hline Body height $(\mathrm{cm})$ & 170.1 & 1.6 & 160.0 & 1.2 & 0.000 \\
\hline Body weight (kg) & 82.4 & 3.1 & 77.1 & 3.4 & 0.258 \\
\hline Body mass index $\left(\mathrm{kg} / \mathrm{m}^{2}\right)$ & 28.4 & 0.7 & 30.0 & 1.1 & 0.225 \\
\hline Waist circumference $(\mathrm{cm})$ & 98.4 & 1.8 & 94.4 & 2.3 & 0.181 \\
\hline Systolic blood pressure $(\mathrm{mm} \mathrm{Hg})$ & 140.0 & 3.3 & 137.7 & 3.7 & 0.631 \\
\hline Diastolic blood pressure (mm Hg) & 93.5 & 3.2 & 88.2 & 2.3 & 0.187 \\
\hline Heart rate (beat/min) & 75.1 & 2.5 & 77.7 & 2.2 & 0.448 \\
\hline Fasting sugar (mg/dL) & 112.8 & 5.8 & 105.4 & 5.0 & 0.339 \\
\hline Hemoglobin A1 $c^{c}(\%)$ & 6.4 & 0.3 & 6.3 & 0.2 & 0.684 \\
\hline Triglyceride (mg/dL) & 234.0 & 23.8 & 188.4 & 14.7 & 0.112 \\
\hline $\mathrm{HDL}-\mathrm{c}^{c}(\mathrm{mg} / \mathrm{dL})$ & 41.5 & 1.7 & 49.3 & 2.1 & 0.006 \\
\hline $\mathrm{LDL}-\mathrm{c}^{\mathrm{c}}(\mathrm{mg} / \mathrm{dL})$ & 125.5 & 7.1 & 134.9 & 6.1 & 0.314 \\
\hline Total cholesterol (mg/dL) & 195.2 & 7.7 & 204.9 & 6.2 & 0.333 \\
\hline Alanine aminotransferase (IU/L) & 42.0 & 4.1 & 23.2 & 2.4 & 0.000 \\
\hline Aspartate aminotransferase (IU/L) & 30.1 & 3.1 & 20.5 & 1.6 & 0.008 \\
\hline$\gamma$-Glutamyl transferase (IU/L) & 54.4 & 8.5 & 29.8 & 3.1 & 0.012 \\
\hline Alkaline phosphatase (IU/L) & 161.3 & 7.8 & 142.2 & 9.8 & 0.135 \\
\hline Total bilirubin (mg/dL) & 0.7 & 0.05 & 0.6 & 0.06 & 0.019 \\
\hline Creatinine $(\mu \mathrm{m} / \mathrm{L})$ & 1.1 & 0.03 & 0.8 & 0.02 & 0.000 \\
\hline Uric acid (mg/dL) & 7.8 & 0.29 & 6.1 & 0.27 & 0.000 \\
\hline Insulin ( $\mu \mid \mathrm{U} / \mathrm{mL})$ & 19.4 & 4.7 & 16.5 & 2.0 & 0.566 \\
\hline Homocysteine $(\mu \mathrm{mol} / \mathrm{L})$ & 13.6 & 0.7 & 11.5 & 0.6 & 0.025 \\
\hline Testosterone (ng/dL) & 337.2 & 25.0 & 31.6 & 3.7 & 0.000 \\
\hline Fibrinogen (mg/dL) & 434.5 & 20.7 & 469.8 & 27.0 & 0.308 \\
\hline C-reactive protein $(\mathrm{mg} / \mathrm{dL})$ & 0.28 & 0.06 & 0.51 & 0.12 & 0.001 \\
\hline White blood cell $(\mathrm{k} / \mu \mathrm{L})$ & 7.3 & 0.4 & 7.2 & 0.5 & 0.792 \\
\hline Red blood cell (m/ML) & 5.2 & 0.12 & 4.7 & 0.07 & 0.002 \\
\hline Hemoglobin (g/dL) & 15.3 & 0.2 & 13.7 & 0.2 & 0.000 \\
\hline Platelet $(\mathrm{k} / \mu \mathrm{L})$ & 259.1 & 11.0 & 312.4 & 11.9 & 0.002 \\
\hline $\mathrm{HOMA}^{\mathrm{C}}$ & 4.8 & 1.1 & 3.7 & 0.5 & 0.012 \\
\hline LogHOMA & 0.56 & 0.07 & 0.51 & 0.05 & 0.096 \\
\hline Quicki $^{c}$ & 0.32 & 0.01 & 0.32 & 0.01 & 0.176 \\
\hline McAuley index & 0.55 & 0.03 & 0.59 & 0.03 & 0.043 \\
\hline
\end{tabular}

${ }^{\mathrm{a}} \mathrm{SEM}$ indicates standard error of mean. ${ }^{\mathrm{b}}$ Analyzed by t-test. ${ }^{\mathrm{C}}$ Hemoglobin A1c indicates glycosylated hemoglobin A1c. HDL-c indicates high density lipoprotein cholesterol. LDL-c indicates low density lipoprotein cholesterol. HOMA indicates homeostasis model assessment. Quicki indicates quantitative insulin sensitivity check index.

used to test the significance of these changes. After adjusting for sex and age, the decreases in the incidence rate (standard error, $p$ value) of MetS at visit 2, 3, 4, 5, 6 and 7 from the baseline value (visit 1) were: $7.1 \%$ $(3.7 \%, 0.920), 9.5 \%(4.3 \%, 0.451), 19.0 \%(5.7 \%, \mathbf{0 . 0 2 1})$, $16.7 \%(5.4 \%, \mathbf{0 . 0 4 7}), 11.9 \%(4.7 \%, 0.229)$ and $11.9 \%$ $(4.7 \%, 0.229)$ respectively. The incidence rate was lowest at the end of the three-month supplementation period (visit 4) and was significantly lower than that at the baseline which is $100 \%(p=0.021)$. It still remained significant at visit 5 (one month after the cessation of supplementation) ( $p=0.047)$ but this effect diminished at visit 6 \& 7 (two \& three months after stopping supplementation) $(p>0.05)$. The decreases were not significant when the two genders were analyzed separately.

Except for waist circumference, the remaining four risk factors of MetS did not show significant decreases after WBG supplementation. In contrast, significant decreases in the waist circumference were observed after the intervention (Table 2). Compared to the value at the baseline (visit 1$)$, there were significant decreases in the waist circumference at visit $3(p<0.0001)$, visit 4 ( $p=$ $0.002)$ and visit $5(p=0.042)$.

When women and men were separately analyzed after adjusting for age, the decreases of the waist circumference were still significant (Table 2). Compared to the baseline, 


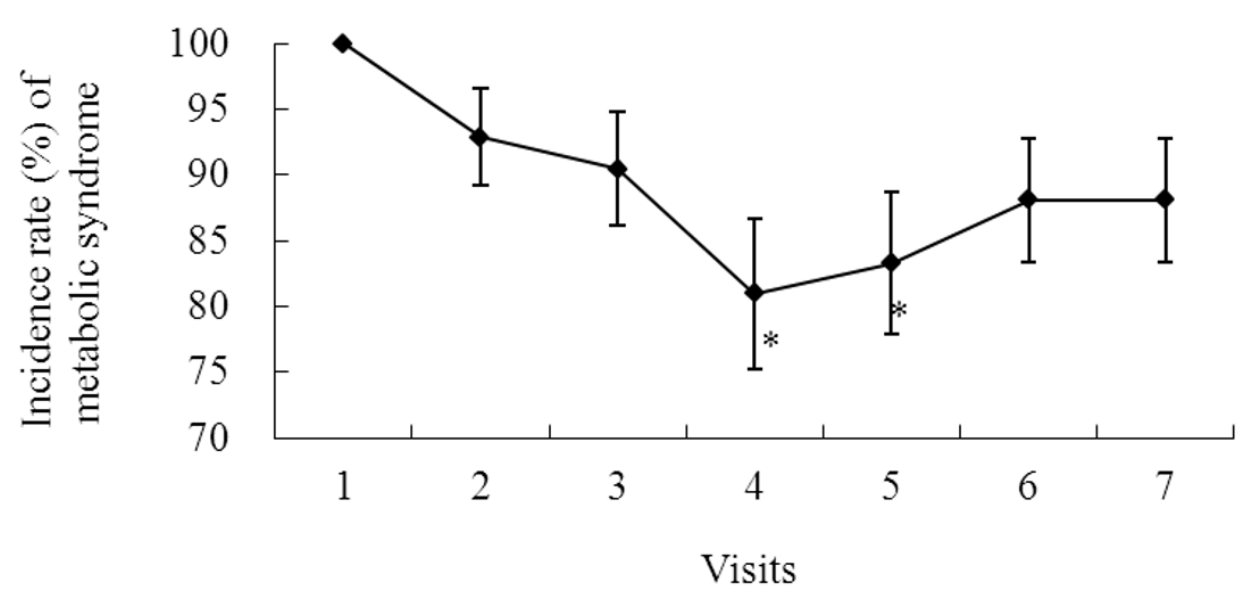

Figure 1 Changes in the incidence rate of metabolic syndrome (MetS) throughout the study period. 42 subjects were supplemented with $4.8 \mathrm{~g} / \mathrm{d}$ wild bitter gourd for three month. Metabolic syndrome was monitored monthly during the three-month supplementation (visit 14) and another three months (visit 5-7) after the supplementation ended. ${ }^{*} p<0.05$ denotes significantly different from the baseline value (visit 1) analyzed by generalized linear mixed models after adjusting for sex and age.

there were significant decreases in the waist circumference for women at visit 3 and visit 4, but not at visit 6 and visit 7. In men, there were significant decreases at visit 2, 3, 5, 6 and 7. Interestingly, there were no significant decreases in BMI after WBG supplementation.

Changes of the three insulin resistance indicators, $\log$ HOMA, Quicki, and McAuley values, throughout the study period are shown in Figure 2. The changes of insulin resistance indicators logHOMA, McAuley, and Quicki implied an ameliorative trend during the supplementation period. Decreased logHOMA and increased Quicki values showed improvement of insulin resistance at visit 2 and returned to nearly baseline level after the cessation of supplementation, but the differences did not reach significant levels $(p>0.05)$. The increasing trend of the McAuley values also suggested the improvement which could be maintained throughout the six month of the study period. The McAuley values were highest at visit 6 (two months after the cessation of supplementation) which was significantly different from that of visit 1. Result of LMM analyses, after adjusting for sex and age, showed the changes of the
HOMA values at visit $2,3,4,5,6$, and 7 from the baseline visit 1 were not significant (data not shown).

\section{Side effect}

There were few adverse events during the study and these were generally mild. Throughout the three-month supplementation period only one subject reported abdominal pain and two claimed bloat. Neither upper respiratory tract infections, rapid weight gain, edema, nor other serious adverse events have been noted during the three-month follow-up period. Two patients dropped out due to persistent dizziness and headache which already disturbed them on and off before entering this study. There were no significant changes in the alkaline phosphatase, $\gamma$-glutamyl transferase, AST, ALT, total bilirubin, creatinine, sodium and potassium levels at visit 4 compared to those at the baseline (visit 1 ).

\section{Discussion}

Results of this preliminary study demonstrate, for the first time, the beneficial effects of WBG in Taiwanese adult subjects with MetS. A daily dose of 4.8 grams

Table 2 Changes of the waist circumference throughout the study period

\begin{tabular}{|c|c|c|c|c|c|c|c|c|c|}
\hline \multirow{2}{*}{$\begin{array}{l}\text { Differences } \\
\text { Between }\end{array}$} & \multicolumn{3}{|c|}{ Women } & \multicolumn{3}{|c|}{ Men } & \multicolumn{3}{|c|}{ Total } \\
\hline & Mean $(\mathrm{cm})$ & SEM $^{a}$ & $p$ value $^{b}$ & Mean $(\mathrm{cm})$ & SEM $^{\mathrm{a}}$ & $p$ value $^{b}$ & Mean $(\mathrm{cm})$ & SEM $^{a}$ & $p$ value $^{b}$ \\
\hline Visit 2-Visit $1^{c}$ & 0.13 & 0.88 & 0.878 & -2.08 & 0.95 & 0.031 & -0.99 & 0.66 & 0.138 \\
\hline Visit 3-Visit 1 & -2.97 & 0.88 & 0.001 & -2.04 & 0.95 & 0.034 & -2.52 & 0.66 & 0.000 \\
\hline Visit 4-Visit 1 & -2.50 & 0.86 & 0.004 & -1.64 & 0.95 & 0.087 & -2.09 & 0.66 & 0.002 \\
\hline Visit 5-Visit 1 & -0.72 & 0.88 & 0.411 & -1.96 & 0.95 & 0.042 & -1.36 & 0.66 & 0.042 \\
\hline Visit 6-Visit 1 & 0.20 & 0.88 & 0.817 & -2.69 & 0.95 & 0.006 & -1.26 & 0.66 & 0.059 \\
\hline Visit 7-Visit 1 & -0.08 & 0.89 & 0.925 & -2.55 & 0.97 & 0.010 & -1.32 & 0.67 & 0.051 \\
\hline
\end{tabular}

${ }^{a}$ SEM indicates standard error of means. ${ }^{b}$ Analyzed by linear mixed models. 


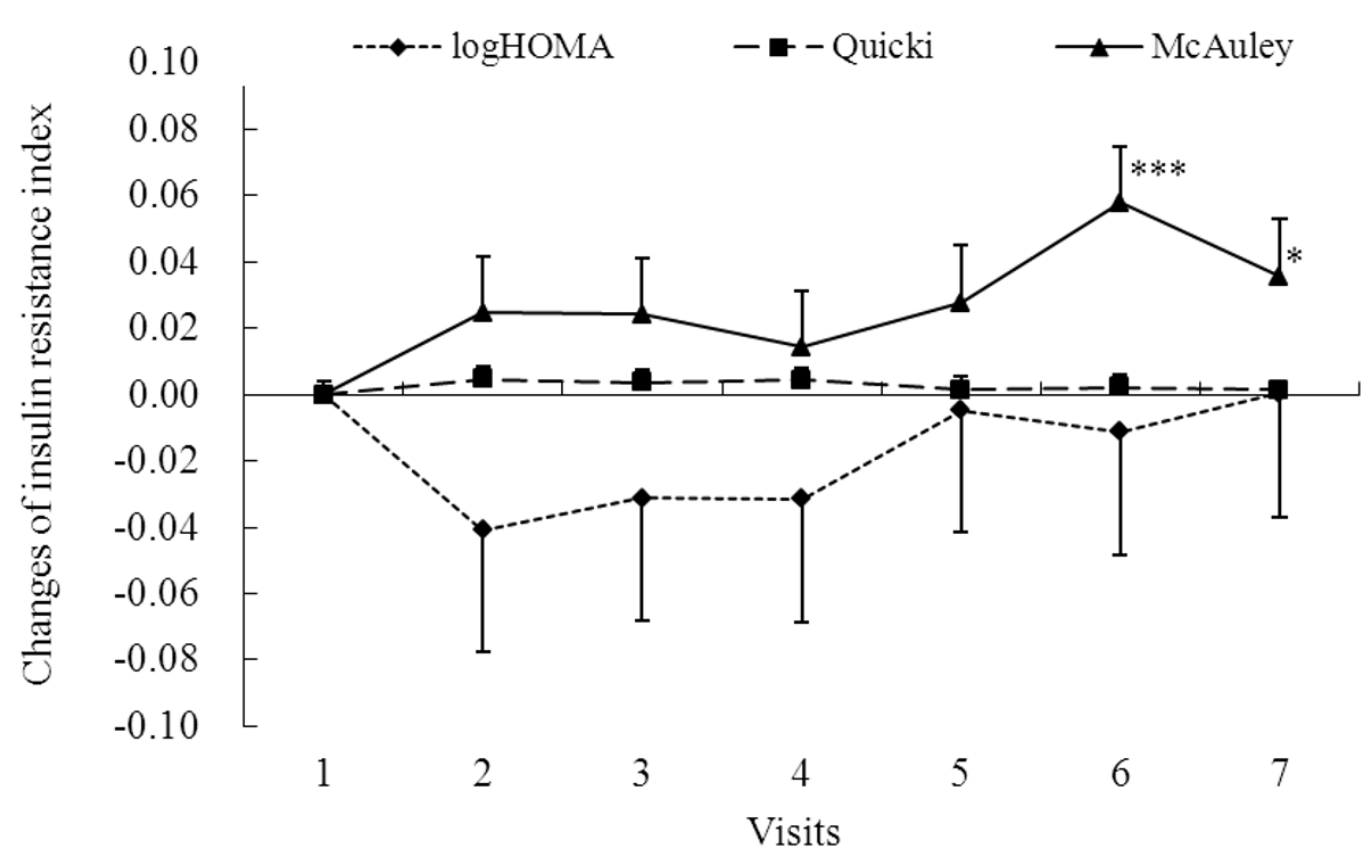

Figure 2 Changes of logHOMA, Quicki and McAuley index, the insulin resistance indicators throughout the study period. 42 subjects were supplemented with $4.8 \mathrm{~g} / \mathrm{d}$ wild bitter gourd for three month. Insulin resistance index was monitored monthly during the three-month supplementation (visit 1-4) and another three months (visit 5-7) after the supplementation ceased. Values are means and error bars are 1/2 SEM. ${ }^{*} p=0.043$ and ${ }^{* *} p=0.001$ denote significantly different from the baseline value (visit 1 ) analyzed by linear mixed models after adjusting for age and sex.

lyophilized WBG powders in capsules significantly decreased the incidence of MetS after three months of supplementation and the improved status remained after stopping the supplementation for one month, but not for two and three months. This indicates that the washout period should be at least one month if a crossover study is to be conducted. Our results show that it is worth to conduct further randomized-placebo controlled trials to confirm the benefits of WBG on metabolic disorders.

MetS is a spectrum of metabolic disorders that project to high risk of type $2 \mathrm{DM}$ and cardiovascular diseases. MetS subjects defined by at least three out of the five risk factors are thus a heterogeneous population. The most common characteristic of our study subjects is abdominal obesity, based on the large waist circumference ( 40 out of the 42 subjects). In this regard, we did observe a significant decrease in waist circumference after the supplementation of WBG. On the other hand, the number of subjects with high serum glucose $(\geq 100$ $\mathrm{mg} / \mathrm{dL})$ and triglyceride $(\geq 150 \mathrm{mg} / \mathrm{dL})$, low HDL-c and high blood pressure (SBP $\geq 130$ or $\mathrm{DBP} \geq 85 \mathrm{mmHg}$ ) were 26 (61.9\%), 34 (81.0\%), 25 (59.5\%) and 36 (85.7\%), respectively. The relatively small sample size together with the heterogeneity might have limited our power to detect differences in these metabolic endpoints.
Insulin resistance is regarded to play a central role in MetS and abdominal obesity has been associated with insulin resistance. Despite that the insulin resistance indicators $\log$ HOMA, McAuley, and Quicki showed ameliorated trends after one to three months of WBG supplementation, there were no statistical significance due to the small sample size and heterogeneous characteristics of our study subjects. Indeed, our original goal was to recruit $45 \mathrm{MetS}$ subjects based on the sample size estimation with a $15 \%$ decrease in the MetS incidence rate after WBG supplementation and 5\% dropout rate. Fortunately, a $19 \%$ decrease in the MetS incidence rate was observed despite that only 42 subjects were recruited and 4 (9.5\%) of them have dropped out.

In addition to the individual differences in MetS risk factors, the heterogeneity of our study subjects also arisen from the great range of their ages (23-63 years) and BMI (22.3-45.2). Moreover, both men and women (irrespective of whether they are post- or pre- menopause) were included. Besides, subjects previously diagnosed with type $2 \mathrm{DM}$, hyperlipidemia or hypertension were not excluded and were all advised to maintain their prescribed medication. These further increased the heterogeneity of our study subjects. All these heterogeneities should be avoided if a randomized controlled trial is to be carried out in the future. 
The regulation of glucose metabolism by BG or it extracts/components has been extensively reviewed and various active compounds and action mechanisms have been proposed [3-5]. Early study isolated a Polypeptide$\mathrm{P}$, the so-called "plant insulin" from BG and demonstrated its insulin-like activity [25]. D-(+)-trehalose isolated from BG was shown to inhibit $\alpha$-glucosidase [26] and delayed the digestion and absorption of dietary carbohydrates. Recently, cucurbitane-type triterpenoids isolated from BG were shown to increase glucose transporter 4 translocation through activation of AMPK [27], inhibit $\alpha$-glucosidase [28], and modulate insulin secretion activity [29]. 9c,11t,13t-conjugated linolenic acid [30] and momordin [31] from BG were noted to activate PPAR $\alpha, \gamma$ and PPAR $\beta / \delta$ respectively. It has been shown that PPAR $\gamma$ agonist induced uncoupling protein-1 expression and increased oxygen consumption in the white adipose tissue cells [32]. In addition, $\mathrm{PPAR} \beta / \delta$ has been shown to play a critical role in the body fat reduction in an animal model [33].

In vivo studies using animal models also provided evidences that BG ameliorated metabolic disorders through the regulations of PPARs as one of the mechanism $[18,34]$. The Hualien No.4 WBG used in this study is a hybrid variety of WBG being selected for its high PPAR activating activity. Other proposed mechanisms for actions of BG include stimulation of pancreatic insulin secretion [35], decreased hepatic gluconeogenesis, increased hepatic glycogen synthesis, metformin- and sulfonylurea-like glycemic control activities [5,36].

Almost all the human studies associated with metabolic disorder using bitter gourd were focused on controlling type 2 DM [3]. The beneficial effects of BG on type $2 \mathrm{DM}$ have not been firmly established. Most noncontrolled, and 2 randomized controlled trials [20,37] showed statistically significant reduction of fasting blood glucose, but other controlled trials showed no significant effect [20].

Among the five criteria of MetS, only waist circumference was found to be significantly reduced after supplementation in this study. This trend of change in the waist circumference was similar to the decline in the incidence rate of MetS, despite that lowering of waist circumference to less than $90 / 80 \mathrm{~cm}$ were not the main contributors for subjects that showed a release from having MetS after three months of BG supplementation. Abdominal obesity is well recognized as a potential etiologic factor of MetS [38]; hence, reverted central obesity is of significance for overall MetS management. This finding from our study is particularly important for Asians, a population that is likely to have metabolic obesity [39].

In general, lyophilized WBG powder capsule preparations in our study were well tolerated. There were few adverse events and these were generally mild. In previous human trials, the most commonly reported side effects are abdominal pain and diarrhea [24]. Our study showed that adverse effects were mostly moderate, including one and two subjects with abdominal pain and bloat respectively. To our knowledge, this is the first human trial to evaluate the effects of WBG on MetS.

\section{Limitation}

Our study, however, has certain limitations. The relatively small sample size and substantial heterogeneity of the studied subjects limited our power to detect differences in many metabolic endpoints. This was an uncontrolled trial, so we cannot exclude the placebo effect. Nevertheless, after discontinuing the supplementation agent, our subjects were followed up for MetS over an additional three-month period. On the other hand, a recent study demonstrated that taking dietary supplements may create an illusory sense of invulnerability that disinhibits unhealthy behaviors because such supplements are perceived as conferring health advantages [40]. This might also be a concern as we did not monitor diets and other life-style factors of our subjects throughout the study period. Generalizability (external validity) of the trial findings were not defined due to the WBG capsules used were prepared from a specific variety of WBG provided by Hualien District Agricultural Research and Extension Station, Council of Agricultural, Executive Yuan, Taiwan.

\section{Conclusions}

Results of this preliminary study demonstrate the beneficial effects of WBG on MetS in human. Daily dose of 4.8 g lyophilized WBG powder significantly decreased the MetS incidence rate after three months of supplementation and this improved status remained for one month, but not additional months, after the supplementation ceased. This indicates that the washout period should be at least one month if a crossover study is to be conducted. Waist circumference also decreased significantly after WBG supplementation. No major adverse effects were observed. Results of this study provide the justification for double-blinded placebo controlled trials in the future.

\section{List of abbreviations used}

BG: bitter gourd; BMI: body mass index; DM: diabetes mellitus; HDL-c: high density lipoprotein cholesterol; GLMM: generalized linear mixed model; HOMA: homeostasis model assessment; LMM: linear mixed model; MetS: metabolic syndrome; PPAR: peroxisome proliferator-activated receptor; Quicki: quantitative insulin sensitivity check index; WBG: wild bitter gourd

\section{Acknowledgements}

This study is financially supported by a grant (NSC97-2317-B-324-003) from the National Science Council, Taiwan. We thank Mr. Jong-Ho Chuan of Hualien District Agricultural Research and Extension Station, Council of Agricultural, Executive Yuan, Taiwan, for providing fresh WBG samples. We 
thank our patients for their cooperative participation, Abby Wu for secretarial assistance, Sheng-Liang Wu for statistical help in the analysis, and the expert assistance of all colleagues from the Health Management Center of Cheng Ching Hospital.

\section{Author details}

'Department of Family Medicine, Cheng Ching Hospital, Taichung 407, Taiwan. ${ }^{2}$ Graduate Institute of Biochemical Sciences and Technology, Chaoyang University of Technology, Wufong, Taichung 41349, Taiwan. ${ }^{3}$ Department of Biochemical Science and Technology, National Taiwan University, Taipei 106, Taiwan. ${ }^{4}$ Institute of Biomedical Nutrition, Hungkuang University, Sha Lu, Taichung 443 Taiwan.

\section{Authors' contributions}

CHT wrote the manuscript, conducted the trial and statistical analysis and interpreted the data. ECFC coordinated the trial. HST and CjH provided critical review of the manuscript. CjH, ECFC and HST designed and supervised the study, obtained funding, interpreted the data, and provided critical review of the manuscript. All authors have read and approved the final manuscript.

\section{Competing interests}

The authors declare that they have no competing interests.

Received: 7 July 2011 Accepted: 13 January 2012 Published: 13 January 2012

\section{References}

1. Grover JK, Yadav SP: Pharmacological actions and potential uses of Momordica charantia: A review. J Ethnopharmacol 2004, 93:123-132.

2. Basch E, Gabardi S, Ulbricht C: Bitter melon (Momordica charantia): A review of efficacy and safety. Am J Health Syst Pharm 2003, 60:356-359.

3. Tsai CH, Chen ECF, Tsay HS, Huang Cj: Bitter Gourd (Momordica charantia): A review of efficacy and safety on glucose homeostasis. Nutr Sci J 2010, 35:115-126.

4. Krawinkel MB, Keding GB: Bitter gourd (Momordica Charantia): A dietary approach to hyperglycemia. Nutrition Reviews 2006, 64:331-337.

5. Yeh GY, Eisenberg DM, Kaptchuk TJ, Phillips RS: Systematic review of herbs and dietary supplements for glycemic control in diabetes. Diabetes Care 2003, 26:1277-1294.

6. Gadang V, Gilbert W, Hettiararchchy N, Horax R, Katwa L, Devareddy L: Dietary bitter melon seed increases peroxisome proliferator-activated receptor-gamma gene expression in adipose tissue, down-regulates the nuclear factor-kappaB expression, and alleviates the symptoms associated with metabolic syndrome. J Med Food 2011, 14:86-93.

7. Shih CC, Lin CH, Lin WL, Wu JB: Momordica charantia extract on insulin resistance and the skeletal muscle GLUT4 protein in fructose-fed rats. J Ethnopharmacol 2009, 123:82-90.

8. Wang ZQ, Zhang XH, Yu Y, Poulev A, Ribnicky D, Floyd ZE, Cefalu WT: Bioactives from bitter melon enhance insulin signaling and modulate acyl carnitine content in skeletal muscle in high-fat diet-fed mice. J Nutr Biochem 2011, 22:1064-1073.

9. Grundy SM, Cleeman JI, Daniels SR, Donato KA, Eckel RH, Franklin BA, Gordon DJ, Krauss RM, Savage PJ, Smith SC Jr, et al: Diagnosis and management of the metabolic syndrome: An American Heart Association/National Heart, Lung, and Blood Institute Scientific Statement. Circulation 2005, 112:2735-2752.

10. Trevisan M, Liu J, Bahsas FB, Menotti A: Syndrome X and mortality: A population-based study. Risk factor and life expectancy research group. Am J Epidemiol 1998, 148:958-966.

11. Mozumdar A, Liguori G: Persistent increase of prevalence of metabolic syndrome among U.S. adults: NHANES III to NHANES 1999-2006. Diabetes Care 2011, 34:216-219.

12. Tsai $C H$, Li TC, Lin CC: Metabolic syndrome as a risk factor for nonalcoholic fatty liver disease. South Med J 2008, 101:900-905.

13. Berger JP, Akiyama TE, Meinke PT: PPARs: Therapeutic targets for metabolic disease. Trends Pharmacol Sci 2005, 26:244-251.

14. Chao CY, Huang Cj: In Vitro activation of peroxisome proliferatoractivated receptor a by some extracts from food materials. J Food Drug Anal 2008, 16:62-69.
15. Chao CY, Huang Cj: Bitter gourd (Momordica charantia) extract activates peroxisome proliferator-activated receptors and upregulates the expression of the acyl CoA oxidase gene in H4IIEC3 hepatoma cells. J Biomed Sci 2003, 10:782-791.

16. Chou YM, Chao CY: Wild bitter gourd extracts activate the transcription factor, PPARY, and inhibit LPS-Induced inflammatory responses in RAW264.7 cells. Nutr Sci J 2008, 33:108-115.

17. Huang $\mathrm{TH}$, Kota BP, Razmovski V, Roufogalis BD: Herbal or natural medicines as modulators of peroxisome proliferator-activated receptors and related nuclear receptors for therapy of metabolic syndrome. Basic Clin Pharmacol Toxicol 2005, 96:3-14

18. Shih CC, Lin CH, Lin WL: Effects of Momordica charantia on insulin resistance and visceral obesity in mice on high-fat diet. Diabetes Res Clin Pract 2008, 81:134-143.

19. Yin J, Zhang $\mathrm{H}$, Ye J: Traditional chinese medicine in treatment of metabolic syndrome. Endocr Metab Immune Disord Drug Targets 2008, 8:99-111.

20. Ooi CP, Yassin Z, Hamid TA: Momordica charantia for type 2 diabetes mellitus. Cochrane database of systematic reviews 2010, CD007845.

21. Tan CE, Ma S, Wai D, Chew SK, Tai ES: Can we apply the National Cholesterol Education Program Adult Treatment Panel definition of the metabolic syndrome to Asians? Diabetes Care 2004, 27:1182-1186.

22. Jayasooriya AP, Sakono M, Yukizaki C, Kawano M, Yamamoto K, Fukuda N: Effects of Momordica charantia powder on serum glucose levels and various lipid parameters in rats fed with cholesterol-free and cholesterol-enriched diets. J Ethnopharmacol 2000, 72:331-336.

23. Liu J, Yang F, Wang T, Cheng C, Shaw N, Kao MD, Chuang CY, Huang CJ: Analysis of vitamin $\mathrm{E}$, selenium, and other nutrients in planned balanced diets in Taiwan. Nutr Sci J 2002, 27:221-231.

24. Patel JC, Dhirawani MK, Doshi JC: "Karella" in the treatment of diabetes mellitus. Indian J Med Sci 1968, 22:30-32.

25. Khanna P, Jain SC, Panagariya A, Dixit VP: Hypoglycemic activity of polypeptide-p from a plant source. J Nat Prod 1981, 44:648-655.

26. Matsuur H, Asakawa C, Kurimoto M, Mizutani J: Alpha-glucosidase inhibitor from the seeds of balsam pear (Momordica charantia) and the fruit bodies of Grifola frondosa. Biosci Biotechnol Biochem 2002, 66:1576-1578.

27. Tan MJ, Ye JM, Turner N, Hohnen-Behrens C, Ke CQ, Tang CP, Chen T, Weiss HC, Gesing ER, Rowland A, et al: Antidiabetic activities of triterpenoids isolated from bitter melon associated with activation of the AMPK pathway. Chem Biol 2008, 15:263-273.

28. Nhiem NX, Kiem PV, Minh CV, Ban NK, Cuong NX, Tung NH, Ha le M, Ha do T, Tai BH, Quang TH, et al: alpha-Glucosidase inhibition properties of cucurbitane-type triterpene glycosides from the fruits of Momordica charantia. Chem Pharm Bull (Tokyo) 2010, 58:720-724.

29. Ma J, Whittaker P, Keller AC, Mazzola EP, Pawar RS, White KD, Callahan JH, Kennelly EJ, Krynitsky AJ, Rader Jl: Cucurbitane-type triterpenoids from Momordica charantia. Planta Med 2010, 76:1758-1761.

30. Chuang CY, Hsu C, Chao CY, Wein YS, Kuo YH, Huang Cj: Fractionation and identification of $9 \mathrm{c}, 11 \mathrm{t}, 13 \mathrm{t}$-conjugated linolenic acid as an activator of PPARa in bitter gourd. J Biomed Sci 2006, 13:763-772.

31. Sasa M, Inoue I, Shinoda Y, Takahashi S, Seo M, Komoda T, Awada T, Katayama S: Activating Effect of Momordin, Extract of Bitter Melon (Momordica Charantia L.), on the Promoter of Human PPARdelta. J Atheroscler Thromb 2009, 16:888-892.

32. Vernochet C, Peres SB, Davis KE, McDonald ME, Qiang L, Wang H, Scherer PE, Farmer SR: C/EBPalpha and the corepressors CtBP1 and CtBP2 regulate repression of select visceral white adipose genes during induction of the brown phenotype in white adipocytes by peroxisome proliferator-activated receptor gamma agonists. Mol Cell Biol 2009, 29:4714-4728.

33. Lee JH, Jun HJ, Jia Y, Kim W, Choi SG, Lee SJ: Critical role of peroxisome proliferator activated receptor-delta on body fat reduction in C57BL/6 and human apolipoprotein E2 transgenic mice fed delipidated soybean. J Agric Food Chem 2011, 59:11872-11881.

34. Kumar R, Balaji S, Uma TS, Sehgal PK: Fruit extracts of Momordica charantia potentiate glucose uptake and up-regulate Glut-4, PPAR gamma and PI3K. J Ethnopharmacol 2009, 126:533-537.

35. Welihinda J, Karunanayake EH, Sheriff MH, Jayasinghe KS: Effect of Momordica charantia on the glucose tolerance in maturity onset diabetes. J Ethnopharmacol 1986, 17:277-282. 
36. Rotshteyn Y, Zito SW: Application of modified in vitro screening procedure for identifying herbals possessing sulfonylurea-like activity. J Ethnopharmacol 2004, 93:337-344.

37. Inayat ur R, Malik SA, Bashir M, Khan R, lqbal M: Serum sialic acid changes in non-insulin-dependant diabetes mellitus (NIDDM) patients following bitter melon (Momordica charantia) and rosiglitazone (Avandia) treatment. Phytomedicine 2009, 16:401-405.

38. Robinson LE, Graham TE: Metabolic syndrome, a cardiovascular disease risk factor: Role of adipocytokines and impact of diet and physical activity. Can J Appl Physiol 2004, 29:808-829.

39. Lear SA, Humphries KH, Kohli S, Chockalingam A, Frohlich JJ,

Birmingham CL: Visceral adipose tissue accumulation differs according to ethnic background: results of the Multicultural Community Health Assessment Trial (M-CHAT). Am J Clin Nutr 2007, 86:353-359.

40. Chiou WB, Yang CC, Wan CS: Ironic effects of dietary supplementation: Illusory invulnerability created by taking dietary supplements licenses health-risk behaviors. Psychol Sci 2011, 22:1081-1086.

doi:10.1186/1475-2891-11-4

Cite this article as: Tsai et al.: Wild bitter gourd improves metabolic syndrome: A preliminary dietary supplementation trial. Nutrition Journal 2012 11:4.

\section{Submit your next manuscript to BioMed Central} and take full advantage of:

- Convenient online submission

- Thorough peer review

- No space constraints or color figure charges

- Immediate publication on acceptance

- Inclusion in PubMed, CAS, Scopus and Google Scholar

- Research which is freely available for redistribution

Submit your manuscript at www.biomedcentral.com/submit 